\title{
HUBUNGAN PARITAS DENGAN KEJADIAN INKONTINENSIA URIN-STRES PADA WANITA USIA 40-45 Tahun
}

\author{
Correlation Parity With The Incidence Of Urinary Incontinence-Stress In Women Age 40-45 \\ Years In Jaddih Timur
}

\author{
Ervi Suminar, ${ }^{1}$, Lailatul Islamiyah ${ }^{2}$ \\ 'Program Studi Ilmu Keperawatan Universitas Muhammadiyah Gresik \\ Program Studi Ilmu Keperawatan Stikes Insan Se Agung Bangkalan \\ Alamat Korespondensi : Prodi Ilmu Keperawatan dan Ners \\ Jl. Proklamasi No. 54 Gresik \\ e-mail: ervi.suminar@umg.ac.id
}

\begin{abstract}
ABSTRAK
Paritas tinggi merupakan salah satu pencetus terjadinya inkontinensia urin. Pada wanita riwayat paritas tinggi biasanya saat batuk, tertawa, bersin, berolahraga akan mengeluarkan urin dalam jumlah sedikit akibat proses persalinan yang pernah dialami. Tujuan penelitian ini adalah untuk mengetahui hubungan Paritas dengan Kejadian Inkontinensia Urin-stress pada Wanita Usia 40-45 Tahun di Dusun Jaddih Timur.

Jenis penelitian ini adalah penelitian analitik dengan desain cross sectional. Populasi penelitian adalah seluruh wanita usia 40-45 Tahundi Dusun Jaddih Timur Desa Jaddih sebanyak 40 responden. Besar sampel sebanyak 36 responden dengan teknik pengambilan menggunakan Purposive sampling. Pengumpulan data menggunakan kuesioner.Uji statistik yang digunakan adalah Uji Fishers Exact Test dengan $a=0,05$.

Hasil penelitian menunjukkan 16 wanita dengan grandemultipara yang tidak mengalami inkontinensia urin stres sebanyak $0(0 \%)$ dan yang mengalami inkontinensia urin sebanyak 16 $(100 \%)$. Hasil uji Fishers Exact Test di dapatkan p value $=0,002<a(0,05)$, berarti H0 di tolak dan H1 di terima yang berarti ada hubungan paritas dengan kejadian inkontinensia urin-stres pada wanita usia 40-45 tahun.

Berdasarkan hasil penelitian, maka disarankan alternatif yang dapat digunakan untuk menangani atau mencegah inkontinensia urin-stres pada wanita yaitu dengan mengajarkan wanita untuk melakukan latihan dasar pelvis untuk menguatkan otot-otot rangka pada dasar pelvis .
\end{abstract}

Kata Kunci: Paritas, Inkontinensia Urin-Stres

The high parity is one of the origenarators of urinary incontinence. In women with a high history usually when cough, laugh, sneeze, exercise will remove the urine in small amount due to the birth process has ever experienced. The purpose of this study was to determine the relationship of parity with genesis in women age 40-45 years in Jaddih Timur Jaddih Village Socah Sub district Bangkalan regency.

The type of this research is analytic research with cross sectional design. The research populations are all women age 40-45 years in Jaddih Timur Jaddih Villa is 40 respondents. The total of sample is 36 respondents with the technique of using Purpossive Sampling. Data collection used the questionnaries. The statistical test used was Fishers Exact Test a =0,05.

The result of research showed 16 women with grandemultipara who dit not experience urinary incontinence-stress much as $0(0 \%)$ and those with urinary incontinence-stress were 16 $(16 \%)$. From the result of Fihers Exact Test in get $p$ value $=0,002<a(0,05)$ means $H O$ is rejected and $\mathrm{HI}$ is received is a correlation parity with the incidence of urinary incontinence-stress in women age 40-45 years.

Based on the results of research, then suggested alternatives that can be used to handle or prevent urinary incontinence in the elderly is to teach women to perform pelvic floor exercises to strengthen the muscles of the pelvic.

Keyword : Parity, Urinary Incontinence-stress 


\section{PENDAHULUAN}

Paritas atau banyaknya kelahiran merupakan penyebab umum terjadinya inkontinensia stres pada wanita.Keadaan ini terkait dengan melemahnya otot-otot destrusor pasca persalinan yang dialami oleh wanita yang kemudian menyebabkan menurunnya kontrol spincter uretra untuk mempertahakan urin saat bladder terisi oleh urin. Pada wanita riwayat paritas tinggi biasanya saat batuk, tertawa, bersin, berolahraga akan mengeluarkan urin dalam jumlah sedikit akibat proses persalinan yang pernah dialami. Hal tersebut biasa disebut dengan jenis inkontinensia stres.

Kondisi inkontinensia urin karena paritas ini jika terjadi pada perempuan usia 4045 tahun dimana mereka mengalami fase pre menopause (Kasdu, 2007) juga akan memperberat keadaan untuk memungkinkan terjadinya inkontinensia urin stres dimana juga terjadi proses fisiologis penurunan produksi hormon-hormon termasuk penurunan estrogen sehingga resiko terjadinya inkontinensia stres semakin tinggi.

Data di Amerika Serikat diperkirakan sekitar 10-12 juta orang dewasa wanita mengalami inkontinensia urine. Tingkat keparahannya meningkat seiring bertambahnya usia dan paritas. Pada usia 15 tahun atau lebih didapatkan kejadian 10\%, sedang pada usia 35-65 tahun mencapai 12\%. Prevalensi akan meningkat sampai 16\% pada wanita usia lebih dari 65 tahun. Pada multipara didapatkan kejadian 5\%, pada wanita dengan anak satu mencapai $10 \%$ dan meningkat sampai $20 \%$ pada wanita dengan 5 anak (Collein, 2012)

Dari hasil studi pendahuluan melalui wawancara terhadap 10 wanita usia 40-45 tahun yang berada di Dusun Jaddih Tengah Desa Jaddih Kecamatan Socah Kabupaten Bangkalan tanggal 7 Februari 2017, yaitu 30\% wanita tidak mengalami inkontinensia urin stres dan $70 \%$ mengalami inkontinensia urin stres dengan rincian status paritas 1 orang dengan primipara, 4 orang dengan multipara, 2 orang dengan grandemultipara mengalami inkontinensia urin stres.

Seiring dengan bertambahnya usia, ada beberapa perubahan pada anatomi dan fungsi organ kemih, begitu pula yang terjadi pada wanita yang pernah memiliki riwayat persalinan (paritas) selama hidupnya, akan beresiko mengalami inkontinensia urin stres. Melahirkan, terutama melalui proses normal, merupakan penyebab umum terjadinya inkontinensia stres antara lain disebabkan melemahnya otot dasar panggul, kebiasaan mengejan yang salah ataupun karena penurunan estrogen. Kelemahan otot dasar panggul dapat terjadi karena kehamilan, setelah melahirkan, kegemukan (obesitas), menopause, usia lanjut, kurang aktivitas dan operasi vagina. Penambahan berat dan tekanan selama kehamilan dapat menyebabkan melemahnya otot dasar panggul karena ditekan selama sembilan bulan. Proses persalinan juga dapat membuat otot totot dasar panggul rusak akibat regangan otot dan jaringan penunjang serta robekan jalan lahir, sehingga dapat meningkatkan risiko terjadinya Inkontinensia urin (Setiati dan Pramantara 2007). 


$$
\text { Adapun penatalaksanaan non }
$$
farmakologi dari inkontinensia urin adalah dengan latihan bladder training, tujuan terapi ini untuk memperpanjang interval berkemih yang normal dengan teknik distraksi atau teknik relaksasi sehingga frekuensi berkemih hanya 6-7 kali per hari atau 3-4 jam sekali (Setiati, 2007).

Metode lain yang dapat digunakan untuk mencegah inkontinensia urin adalah dengan latihan kegel. Latihan kegel sendiri adalah latihan yang didesain oleh Arnold Kegel untuk memperkuat Pubococcygeus, otot seksual, uterus dan rectum (Hafifah, 2010). Latihan penguatan otot dasar panggul (kegel exercise) dengan cara mengkontraksikan dan merileksasikan otot dasar panggul. Teknik ini spesifik untuk mengatasi masalah stres inkontinensia.Angka keberhasilan 10-94\% ${ }^{(6)}$.

\section{METODE PENELITIAN}

Jenis penelitian ini analitik dengan desain cross sectional. Populasi penelitian ini semua wanita di Dusun Jaddih Timur yang yang pernah melahirkan secara pervaginam berjumlah 40 wanita. Jumlah sampel penelitian 36 wanita dengan menggunakan tekhnik purposive sampling. Instrumen penelitian menggunakan kuesioner dilakukan dengan cara wawancara.

\section{HASIL DAN PEMBAHASAN}

\section{Data Umum}

1. Umur

Tabel 1.Distribusi frekuensi umur wanita

\begin{tabular}{ccc}
\hline \multicolumn{1}{c}{ Usia } & (f) & $(\mathbf{\% )}$ \\
\hline 40 & 1 & 2,8 \\
\hline 41 & 2 & 5,6 \\
\hline 42 & 2 & 5,6 \\
\hline
\end{tabular}

\begin{tabular}{rrrr}
\hline 43 & 8 & 22,2 \\
\hline 44 & 11 & 30,6 \\
\hline 45 & 12 & 33,3 \\
\hline Jumlah & 36 & 100 \\
\hline
\end{tabular}

Sumber : Data Primer 2017

Berdasarkan tabel 1 dari 36 wanita di

Dusun Jaddih Timur menunjukkan bahwa prosentase terbesar dari umur wanita adalah umur 45 tahun $(33.3 \%)$.

2. Tingkat Pendidikan

Tabel 2 Distribusi frekuensi tingkat pendidikan wanita

\begin{tabular}{lcc}
\hline $\begin{array}{l}\text { Tingkat } \\
\text { Pendidikan }\end{array}$ & $\begin{array}{r}\text { Frekuensi } \\
\text { (f) }\end{array}$ & $\begin{array}{r}\text { Persentase } \\
\text { (\%) }\end{array}$ \\
\hline $\begin{array}{l}\text { Tidak } \\
\text { Sekolah }\end{array}$ & 10 & 27,8 \\
\hline SD & 12 & 33,3 \\
\hline SMP & 11 & 30,6 \\
\hline SMA & 3 & 8,3 \\
\hline Jumlah & 36 & 100 \\
\hline Sumber : Data Primer 2017 &
\end{tabular}

Berdasarkan tabel 2 dari 36 wanita di Dusun Jaddih Timur menunjukkan prosentase terbesar dari pendidikan yaitu berpendidikan sekolah dasar (SD) sebanyak 12 responden $(33.3 \%)$.

3. Tingkat Pekerjaan

Tabel 3. Distribusi frekuensi pekerjaan wanita di Dusun Jaddih Timur Maret 2017

\begin{tabular}{lcc}
\hline Pekerjaan & Frekuensi(f) & Persentase(\%) \\
\hline IRT & 20 & 55,6 \\
\hline Petani & 10 & 27,8 \\
\hline Pedagang & 5 & 13,9 \\
\hline Tidak Bekerja & 1 & 2,8 \\
\hline Jumlah & 36 & 100 \\
\hline
\end{tabular}

Sumber : Data Primer 2017

Berdasarkan tabel 3 dari 36 wanita usia 40-45 tahun di Dusun Jaddih Timur menunjukkan sebagian besar adalah seorang ibu rumah tangga yaitu berjumlah 20 orang $(55.6 \%)$. 


\section{Data Khusus}

1. Paritas Wanita

Tabel 4. Distribusi frekuensi status paritas wanita

\begin{tabular}{lcc}
\hline Status Paritas & (f) & $\mathbf{( \% )}$ \\
\hline Nulipara & 3 & 8,3 \\
\hline Primipara & 4 & 11,1 \\
\hline Multipara & 13 & 36,1 \\
\hline Grande Multipara & 16 & 44,4 \\
\hline \multicolumn{1}{c}{ Jumlah } & 36 & 100 \\
\hline
\end{tabular}

Sumber : Data Primer 2017

Berdasarkan tabel 5 dari 36 wanita usia 40-45 tahun di Dusun Jaddih Timur berdasarkan status paritasnya sebagian besar memiliki riwayat paritas grandemultipara (memiliki $>5$ anak) sebanyak 16 responden $(44.4 \%)$.

2. Inkontinensia Urin Stres

Tabel 5. Distribusi frekuensi kejadian inkontinensia urin-stres pada wanita

\begin{tabular}{lcc}
\hline Kejadian & (f) & (\%) \\
\hline $\begin{array}{l}\text { Tidak } \\
\text { Inkontinensia } \\
\text { Urine Stres }\end{array}$ & 4 & 11,1 \\
\hline $\begin{array}{l}\text { Inkontinensi } \\
\text { Urine Stres }\end{array}$ & 32 & 88,9 \\
\hline Jumlah & 36 & 100 \\
\hline Sumber
\end{tabular}

Sumber : Data Primer 2017

Berdasarkan tabel 5 dari 36 wanita usia 40-45 tahun di Dusun Jaddih Timur dilihat dari kejadian inkontinensia urin, sebagian besar mengalami inkontinensia urinstres yaitu 32 responden (88.9\%).

3. Tabulasi Silang

Berdasarkan hasil uji Fishers Exact Test diperoleh $\mathrm{p}=0.002$ yang lebih kecil dari pada tingkat signifikansi $\alpha=0,05$ yang berarti H0 d tolak, hal ini menunjukkan bahwa ada hubungan antara paritas dengan kejadian inkontinensia urin-stres pada wanita usia 4045 tahun di Dusun Jaddih Timur Desa Jaddih
Kecamatan Socah Kabupaten Bangkalan

Maret 2017.

Tabel 6.Tabulasi silang hubungan paritas dengan kejadian inkontinensia urin-stres pada wanita

\begin{tabular}{llll}
\hline \multirow{4}{*}{ Paritas } & \multicolumn{2}{c}{ Kejadian } & \\
\cline { 2 - 3 } & Tidak & Terjadi & \multirow{2}{*}{ Total } \\
& Terjadi & Inkonte & \\
& Inkonte & nensia & \\
& nensia & Urine & \\
& Urine & Stress & \\
& Stress & & \\
\hline
\end{tabular}

\begin{tabular}{lllllll}
\hline Nulipara & 2 & 7 & 1 & 3 & 3 & 100 \\
\hline Primipara & 2 & 50 & 2 & 50 & 4 & 100 \\
\hline Multipara & 0 & 0 & 13 & 100 & 13 & 100 \\
\hline $\begin{array}{l}\text { Grande } \\
\text { Multipara }\end{array}$ & 0 & 0 & 16 & 100 & 16 & 100 \\
\hline Total & 4 & 11 & 32 & 89 & 36 & 100 \\
\hline \multicolumn{5}{c}{ Dari hasil tabulasi silang menunjukkan }
\end{tabular}

16 wanita dengan grandemultipara yang tidak mengalami inkontinensia urin stres sebanyak 0 $(0 \%)$ dan yang mengalami inkontiensia urin stres sebanyak 16 (100\%).

\section{Paritas}

Dari hasil penelitian menunjukkan bahwa dari 36 wanita di Dusun Jaddih Timur sebanyak 16 (44.4\%) memiliki riwayat paritas grandemultipara.

Faktor-faktor yang mempengaruhi paritas adalah pendidikan, pekerjaaan, keadaan ekonomi, latar belakang budaya dan pengetahuan (Manuaba, 2008). Hal ini dikarenakan pendidikan berarti bimbingan yang diberikan oleh seseorang terhadap perkembangan orang lain menuju ke arah suatu cita-cita tertentu. Makin tinggi tingkat pendidikan seseorang, maka makin mudah dalam memperoleh menerima informasi, sehingga kemampuan ibu dalam berpikir lebih rasional. Ibu yang mempunyai pendidikan 
tinggi akan lebih berpikir rasional bahwa jumlah anak yang ideal adalah 2 orang. Hal ini ditunjang dengan adanya data pada tabel 2 menunjukkan bahwa paling banyak pendidikan orang tua $33.3 \%$ sekolah dasar (SD) yaitu 12 orang.

Berdasarkan karakteristik di atas dapat disimpulkan bahwa pendidikan dapat mempengaruhi perilaku responden. Makin tinggi tingkat pendidikan seseorang, maka makin mudah dalam memperoleh dan menerima informasi, sehingga kemampuan ibu dalam berpikir lebih rasional dan mampu mengambil keputusan yang baik untuk menentukan jumlah anak yang ideal sesuai dengan tingkat pengetahuan mereka.

Status ekonomi yang tinggi dan pekerjaan yang mapan juga dapat mempengaruhi jumlah anak yang dimiliki oleh seseorang.Karena mereka merasa mampu untuk membiayai dan menghidupi anak-anak mereka dengan layak, sehingga mereka memutuskan untuk memiliki lebih dari 2 orang anak. Namun tanpa disadari, kebudayaan telah menanamkan garis pengaruh sikap terhadap berbagai masalah, termasuk juga dalam menentukan jumlah anak. Bagi masyarakat di Dusun Jaddih Timur dengan status ekonomi menengah kebawah dan sebagian besar ibu rumah tangga, petani, pedagang bahkan ada beberapa yang tidak bekerja menganggap bahwa semakin banyak jumlah anak yang dimiliki maka semakin banyak rezeki yang akan didapatkan karena setiap anak yang terlahir ke dunia sudah memiliki rejekinya masing-masing sehingga mereka tidak pernah merasa khawatir tidak bisa menghidupi anak-anak mereka.
Berdasarkan hal tersebut status ekonomi dan pekerjaan bukan merupakan kendala besar bagi mereka untuk membatasi jumlah anak yang mereka miliki, sehingga tidak jarang dari masyarakat di Dusun Jaddih Timur yang memiliki riwayat paritas grandemultipara.

\section{Inkontinensia Urin Stres}

Dari hasil penelitian pada tabel 5.6. menunjukkan bahwa dari 36 wanita di Dusun Jaddih Timur sebanyak 32 (88.9\%) mengalami inkontinensia urin stres dan hanya $4 \quad(11.1 \quad \%) \quad$ yang tidak mengalami inkontinensia urin stres.

Seseorang dikatakan inkontinensia urin stres apabila mengalami salah satu dari gejala Inkontinensia stres, dicirikan dengan keluarnya sejumlah kecil urin ketika tertawa, bersin, melompat, batuk atau membungkuk (Stockslager, 2008).

Wanita sering mengeluh kebocoran sedikit urine saat melakukan aktivitas, seperti bermain dengan anak, berlari, melompat, tertawa, menari, dan lain-lain.Hal ini biasanya merupakan kombinasi faktor yang dapat menyebabkan otot dasar panggul melemah dimana kondisi ini dikaitkan dengan persalinan pervagina (paritas). Inkontinensia stres lebih banyak terjadi pada wanita kurang dari usia 65 tahun (Andrews, 2010)

Banyaknya wanita yang mengalami inkontinensia urin di masa premenaupause disebabkan oleh riwayat paritas yang dialami oleh wanita tersebut. Grandemultipara dan multipara merupakan salah satu penyebab terjadinya inkontinensia urin pada wanita usia 
40-45 tahun, karena paritas atau riwayat persalinan dapat menyebabkan lemahnya otototot penunjang pelvis (otot destrusor) sehingga ketika bladder terisi urin terjadi penurunan kendali volunter spincter uretra untuk mempertahankan urin yang pada akhirnya menyebabkan terjadinya inkontinensia urin.

\section{Hubungan Paritas Dengan Kejadian \\ Inkontinensia Urin Stres}

Dari hasil tabulasi silang menunjukkan 16 wanita dengan grandemultipara yang tidak mengalami inkontinensia urin stres sebanyak 0 $(0 \%)$ dan yang mengalami inkontiensia urin stres sebanyak $16(100 \%)$.

Inkontinensia urin lebih sering ditemukan pada wanita dengan jumlah anak yang banyak. Ada yang mengatakan bahwa jarak antara riwayat persalinan pertama dengan persalinan berikutnya akan mempengaruhi risiko terjadinya inkontinensia urin sebesar $30 \%$. Perubahan degeneratif pada sistem persarafan otonomik dari saluran kemih bagian bawah atau tekanan mekanik yang ditimbulkan oleh kehamilan itu sendiri mungkin merupakan faktor-faktor yang dapat mempengaruhi timbulnya inkontinensia urin.Denervasi parsial dari otot-otot dasar panggul diperkirakan adanya kerusakan pada nervus pudendus yang disebabkan baik oleh karena persalinan atau peregangan pada abdomen yang terlalu lama. Kerusakan jaringan ikat pada persalinan ini dapat mempengaruhi daya penyangga pada bagian leher kandung kencing yang dapat menyebabkan stres inkontinensia, amat mungkin dikarenakan jaringan ikat parauretral yang menjadi lebih kaku atau kelemahan dari fasia (Tendeen, 2007).

Hal ini juga sejalan dengan penelitian yang dilakukan Tendeen (2007) di bagian obstetrik \& ginekologi, FK Ustrat/RSU Prof. Dr. R.D. Kandau, Manado bahwa wanita yang memiliki 3 anak atau lebih memiliki angka kejadian inkontinensia urin yang lebih tinggi.

Metode yang dapat digunakan untuk mencegah inkontinensia urin adalah dengan latihan kegel.Latihan kegel sendiri adalah latihan yang didesain oleh Arnold Kegel untuk memperkuat Pubococcygeus, otot seksual, uterus dan rectum (Hafifah, 2010). Latihan penguatan otot dasar panggul (kegel exercise) dengan cara mengkontraksikan dan merileksasikan otot dasar panggul. Teknik ini spesifik untuk mengatasi masalah stres inkontinensia.Angka keberhasilan 10-94 \% (Sarwono, 2010).

Program KB (Keluarga Berencana) juga dibutuhkan dalam hal ini sebagai pengatur jumlah anak yang ideal dimiliki oleh masyarakat untuk kesejahteraan hidup dan kesehatan masyarakat. Dengan diaktifkannya program KB, kemungkinan jumlah masyarakat memiliki anak lebih dari 2 (multipara atau grandemultipara) akan berkurang dan hal tersebut dapat memperkecil kemungkinan terjadinya inkontinensia urin stres pada masyarakat saat usia 40-45 tahun yang disebabkan oleh faktor paritas.

Penilaian-penilaian dari masyarakat tentang fenomena inkontinesia urin-stres merupakan dampak dari rendahnya tingkat pendidikan dan pengetahuan masyarakat tentang masalah kesehatan pada wanita. Hal 
ini dapat juga disebabkan oleh kurang aktifnya tenaga kesehatan dan pemimpin wilayah setempat untuk memberikan fasilitas berupa penyuluhan masalah kesehatan yang mungkin muncul pada wanita beserta cara pencegahan dan penanganan yang dapat diupayakan oleh masyarakat untuk menanggulangi inkontinensia urin-stres dan masalah kesehatan yang lain pada wanita.

\section{KESIMPULAN}

Status paritas pada wanita usia 40-45 tahun di Dusun Jaddih Timur Desa Jaddih Kecamatan Socah Kabupaten Bangkalan yaitu sebagian besar memiliki riwayat paritas grandemultipara (memiliki $>5$ orang anak sebanyak 16 wanita (44.4\%).

Kejadian inkontinensia urin stres pada wanita usia 40-45 tahun di Dusun Jaddih Timur Desa Jaddih Kecamatan Socah Kabupaten Bangkalan yaitu sebagian besar mengalami inkontinensia urin stres sebanyak 32 wanita $(88.9 \%)$.

Ada hubungan antara paritas dengan kejadian inkontinensia urin stres pada wanita usia 40-45 tahun di Dusun Jaddih Timur Desa Jaddih Kecamatan Socah Kabupaten Bangkalan dengan nilai $\mathrm{p}=0.002<\alpha=0,05$.

\section{SARAN}

\section{Bagi Masyarakat}

Sebagai masukan untuk mengatur jumlah anak dengan mengikuti program Keluarga Berencana (KB) dan juga dianjurkan untuk melakukan latihan otot dasar panggul (senam keagel) sebagai pencegahan terhadap inkontinensia urin stres pada saat seiring bertambahnya usia.

\section{Bagi Keluarga}

Melalui hasil penelitian ini diharapkan bagi keluarga untuk meningkatkan perannya dalam memberikan motivasi bagi anggota keluarganya yang telah mengalami inkontinensia urin stres untuk mencari alternatif pengobatan untuk menangani inkontinensia urin yang dialami oleh wanita tersebut dan keluarga juga bisa memberikan dukungan psikologis untuk meningkatkan kepercayaan diri dari wanita yang mengalami inkontinensia urin agar tidak merasa malu untuk mengungkapkan keluhannya dan tetap optimis menghadapi hidup di masa tuanya.

\section{Bagi Profesi}

Disarankan bagi para perawat dan tenaga kesehatan lainnya untuk lebih meningkatkan pemberian pendidikan kesehatan pada masyarakat khususnya kesehatan pada wanita.

4. Bagi Institusi Kesehatan

Hasil penelitian ini selanjutnya dapat digunakan sebagai referensi ilmiah tentang hubungan paritas dengan kejadian inkontinensia urin stres pada wanita usia 40-45 tahun, dengan cara diletakkan di perpustakan setempat agar dapat dipelajari oleh mahasiswa yang lainnya.

\section{Bagi Peneliti \\ Perlu dilakukan penelitian lebih lanjut} tentang pentingnya penanganan dan pencegahan inkontinensia urin stres pada wanita melalui latihan otot dasar panggul (senam kegel). 


\section{DAFTAR PUSTAKA}

Andrews, G. (2010). Buku Ajar Kesehatan Reproduksi Wanita. Edisi 2. Buku Kedokteran, Jakarta: EGC.

Baziad, A. (2008). Kontrasepsi Hormonal. PT Bina Pustaka Sarwono Prawirohardjo. Jakarta.

Collein.I. (2012). Pengalaman Lansia dalam Penanganan Inkontinensia Urine di Wilayah Kerja Puskesmas Kamonji. Jurnal Keperawatan Soedirman (The SoedirmanJournal of Nursing), Volume 7, No.3, November 2012. Diakses pada 21 Oktober 2016 jam 10:26 WIB.

Hafifah. (2010). Lanjut Usia dan Perawatan Gerontik. Yogyakarta: Nuha Medika

Kasdu. (2007). Kiat sehat dan bahagia di usia menopouse. Puspa Swara. Jakarta.

Manuaba, IBG. (2008). Konsep Obstetri dan Ginekologi Sosial Indonesia. Jakarta: EGC

Maryam, R.S dan dkk. (2010). Asuhan Keperawatan Pada Lansia. Jakarta: Trans Info Medika.

Sarwono, P. (2007). Menopause Datang, Rasa Senang Tertendang. Yayasan Bina Pustaka. Jakarta.

Setiati S, dkk. (2007) Buku Ajar Ilmu Penyakit Dalam. Jilid III. Ed IV. Jakarta: Departemen Ilmu Penyakit Dalam Fakultas Kedokteran Universitas Indonesia.

Setiati S. dan Pramantara I.D.P (2007). Inkontinensia Urin dan Kandung Kemih Hiperaktif. Dalam: Aru W. Sudoyo, Bambang S, Idrus Alwi, Marcellus S.K, Siti Setiati. Ilmu Penyakit Dalam FKUI. Edisi IV. Jakarta: FKUI PP:1392-95.

Stockslager,J. L., Schaeffer, L. (2008).Asuhan Keperawatan Geriatrik : edisi 2. Jakarta: EGC.
Sunaryo., dkk.(2016). Asuhan Keperawatan Gerontik. Yogyakarta: CV ANDI OFFSET.

Tendeen, MM. (2007). Artikel Penelitian. Urinary Inkontinence Detection In Post-Menapause Age Using IIQ-7 and UDI-6: Vol 6, No 2 :JKM. 